\title{
TAHAPAN PENGAMBILAN KEPUTUSAN
}

\author{
Firwanda Farhan \\ 185100043 \\ Fakultas Komputer \\ firwandafarhan.student@umitra.ac.id
}

\begin{abstract}
Pengambilan keputusan terdiri dari beberapa tahapan. Individu atau kelompok atau organisasi dalam pengambilan suatu keputusan, disadari atau tidak disadari, mengalami satu atau lebih tahapan tersebut sebelum mencapai keputusan tertentu. Masalahnya tahapan tersebut dilalui dengan baik atau ada tahapan yang terlewati, itu soal lain. Banyak pendapat yang dapat diacu terkait tahapan-tahapan dalam proses pengambilan keputusan dalam konteks organisasi. Seperti misalnya pendapat G.R Terry, Peter F Drucker dll. Dari semua pendapat para ahli tentang proses pengambilan keputusan, dapat disimpulkan bahwa tahapan setiap proses pengambilan keputusan senantiasa terdiri dari: Tahap pertama adalah Identifikasi masalah inti/ utama. Untuk apat mengidentifikasi masalah inti atau utama, perlu dipahami lebih dulu apa yang dimaksud dengan masalah. Beberapa ahli mendefinisikan masalah sebagai pertanyaan yang harus dijawab. Ada pula yang mendefinisikan masalah sebagai sebuah kesenjangan antara harapan dan kenyataan yang harus diatasi. Juga ada yang mengartikan masalah sebagai penyimpangan dari kondisi normal. Apapun definisi masalah yang digunakan, bagaimanapun Identifikasi masalah tetaplah merupakan tahapan yang kritis. Sekali terjadi kesalahan dalam penentuan masalah, maka keputusan yang dihasilkan tidak akan pernah dapat memperbaiki keadaan. Ibarat dokter memberikan obat berdasarkan diagnosis penyakit yang salah. Akibatnya, pasien tidak akan sembuh dengan obat tersebut.
\end{abstract}

Kata Kunci : Tahapan Pengambilan Keputusan 


\section{A. PENDAHULUAN}

Identifikasi masalah yang diurakan di atas adalah agar identifikasi dilakukan tidak hanya menyangkut identifikasi masalah baik hasil, sebab maupun faktor-faktornya, tetapi juga meliputi identifikasi kondisi masalah untuk mengetahui kondisi sekarang dan kondisi yang diharap., identifikasi indikasi-indikasi yang berkaitan dengan masalah, dan dapat membedakan antara masalah yang sebenarnya dengan indikasi-indikasinya.

Jadi, dapatlah dikatakan bahwa pada tahap identifikasi, terdapat tiga langkah yang harus dilakukan yaitu 1) langkah orientasi masalah atau langkah menyadari adanya masalah. 2) langkah preferensi, yakni langkah mengumpulkan data dan informasi, dan 3) langkah definisi, yaitu mengklasifikasi, identifikasi dan merumuskan masalah.

Tahap kedua adalah tahap pengumpulan data dan analisis. Pengumpulan data dan analisis pada tahap dua ini berbeda dengan pengumpulan data pada tahap identifikasi masalah. Perbedaannya ada pada tujuan. Tujuan pengumpulan data pada tahap dua ini bertujuan untuk mendapatkan gambaran tentang kemungkinan alternatif solusi yang bisa dilakukan, berikut analisis alternatif terkait konsekuensi-yang timbul dari setiap alternatif.

Tahap ketiga yaitu tahap penentuan alternatif keputusan berikut konsekuensikonsekuensi positif/ negatif setiap alternatif. Sama halnya dengan tahap identifikasi masalah, tahap penentuan alternatif keputusan juga memerlukan data dan informasi. Semakin lengkap data relevan yang tersedia, semakin baik alternatifalternatif keputusan yang dapat dipilih. Brdasarkan data yang diperoleh, dicoba dicari berbagai alternatif keputusan.

\section{B. PEMBAHASAN / STUDI KASUS}

Keputusan adalah proses penelusuran masalah yang berawal dari latar belakang masalah, identifikasi masalah hingga kepada terbentuknya kesimpulan atau rekomendasi. Rekomendasi yang selanjutnya dipakai dan digunakan sebagai pedoman basis dalam pengambilan keputusan. Oleh karena itu begitu besarnya pengaruh akan terjadi jika seandainya rekomendasi yang dihasilkan tersebut terdapat kekeliruan atau adanya kesalahan-kesalahan yang tersembunyi karena faktor ketidak hati-haitan dalam melakukan pengkajian masalah.

Tahap-tahap Pengambilan Keputusan 
guna memudahkan pengambilan keputusan maka perlu dibuat tahaptahap yang bisa mendorong kepada terciptanya keputusan yang diinginkan. Adapun tahap-tahap tersebut adalah:

- mendefinisikan masalah tersebut secara jelas dan gamblang, atau mudah untuk dimengerti.

- membuat daftar masalah yang akan dimunculkan, dan menyusunnya secara prioritas dengan maksud agar adanya sistematika yang lebih terarah dan terkendali.

- melakukan identifikasi dari setiap masalah tersebut dengan tujuan untuk lebih memberikan gambaran secara lebih tajam dan terarah secara lebih spesifik.

- memetakan setiap masalah tersebut berdasarkan kelompoknya masing-masing yang kemudian selanjutnya dibarengi dengan menggunakan model atau alat uji yang akan dipakai.

- memastikan kembali bahwa alat uji yang dipergunakan tersebut telah sesuai dengan prinsip-prinsip dan kaidahkaidah yang berlaku pada umumnya.

C. ID SECURITY

QWTD4452377-ASP-5244107

\section{KESIMPULAN}

Mengambil keputusan merupakan salah satu tahap dalam proses pengambilan keputusan yakni memilih alternatif terbaik. Mengeluarkan keputusan merupakan langkah yang komplit diantara langkahlangkah manajemen yang terdiri dari perencanaan, hingga pengawasan dan penilaian. Kelayakan sebuah keputusan terletak pada pelaksanaannya. Oleh karena itu, keputusan yang dikeluarkan harus terdiri dari beberapa unsur yaitu surat keputusan, orang yang menerima/ melaksanakan keputusan, perencanaan, distribusi tanggung jawab dan wewenang.

\section{E. DISKUSI}

Hasil penelitian yang telah dilakukan bersama rekan saya Ausa'tu Lahu Fir Rizqi Firdaus, maka mendapatkan kesimpulan berupa:

A) Mendefinisikan masalah keputusan

B) Membuat tahap - tahap pengambilan keputusan

\section{F. REFERENCE}

[1] O. M. Febriani and A. S. Putra, "Sistem Informasi Monitoring Inventori Barang Pada Balai Riset Standardisasi Industri Bandar Lampung," J. Inform., vol. 13, no. 1, pp. 90-98, 2014.

[2] A. S. Putra, "Paperplain: Execution Fundamental Create Application With Borland Delphi 7.0 University Of Mitra 
Indonesia," 2018.

[3] A. S. Putra, "2018 Artikel Struktur Data, Audit Dan Jaringan Komputer,” 2018.

[4] A. S. Putra, "ALIAS MANAGER USED IN DATABASE DESKTOP STUDI CASE DB DEMOS."

[5] A. S. Putra, "COMPREHENSIVE SET OF PROFESSIONAL FOR DISTRIBUTE COMPUTING."

[6] A. S. Putra, "DATA ORIENTED RECOGNITION IN BORLAND DELPHI 7.0."

[7] A. S. Putra, "EMBARCADERO DELPHI XE 2 IN GPUPOWERED FIREMONKEY APPLICATION."

[8] A. S. Putra, "HAK ATAS KEKAYAAN INTELEKTUAL DALAM DUNIA TEKNOLOGY BERBASIS REVOLUSI INDUSTRI 4.0."

[9] A. S. Putra, "IMPLEMENTASI PERATURAN

PERUNDANGAN UU. NO 31

TAHUN 2000 TENTANG

DESAIN INDUSTRI

BERBASIS INFORMATION TECHNOLOGY."

[10] A. S. Putra, "IMPLEMENTATION OF PARADOX DBASE."

[11] A. S. Putra, "IMPLEMENTATION OF TRADE SECRET CASE STUDY SAMSUNG MOBILE PHONE."

[12] A. S. Putra, "IMPLEMENTATION

PATENT FOR APPLICATION WEB BASED CASE STUDI WWW. PUBLIKLAMPUNG. COM."
[13] A "IMPLEMENTATION SYSTEM FIRST TO INVENT IN DIGITALLY INDUSTRY."

[14] A. S. Putra, "MANUAL REPORT \& INTEGRATED DEVELOPMENT ENVIRONMENT BORLAND DELPHI 7.0."

[15] A. S. Putra, "PATENT AS RELEVAN SUPPORT RESEARCH."

[16] A. S. Putra, "PATENT FOR RESEARCH STUDY CASE OF APPLE. Inc.”

[17] A. S. Putra, "PATENT PROTECTION FOR APPLICATION INVENT."

[18] A. S. Putra, "QUICK REPORT IN PROGRAMMING.'”

[19] A. S. Putra, "REVIEW CIRCUIT LAYOUT COMPONENT

REQUIREMENT ON ASUS NOTEBOOK."

[20] A. S. Putra, "REVIEW TRADEMARK PATENT FOR INDUSTRIAL TECHNOLOGY BASED 4.0."

[21] A. S. Putra, "TOOLBAR COMPONENT PALLETTE IN OBJECT ORIENTED PROGRAMMING."

[22] A. S. Putra, "WORKING DIRECTORY SET FOR PARADOX 7."

[23] A. S. Putra, "ZQUERY CONNECTION

IMPLEMENTED

PROGRAMMING STUDI CASE PT. BANK BCA Tbk."

[24] A. S. Putra, D. R. Aryanti, and I. Hartati, "Metode SAW (Simple Additive Weighting) 
sebagai Sistem Pendukung

Keputusan Guru Berprestasi (Studi Kasus: SMK Global Surya)," in Prosiding Seminar Nasional Darmajaya, 2018, vol. 1, no. 1, pp. 85-97.

[25] A. S. Putra and O. M. Febriani, "Knowledge Management Online Application in PDAM Lampung Province," in Prosiding International conference on Information Technology and Business (ICITB), 2018, pp. 181-187.

[26] A. S. Putra, O. M. Febriani, and B. Bachry, "Implementasi Genetic Fuzzy System Untuk Mengidentifikasi Hasil Curian Kendaraan Bermotor Di Polda Lampung," SIMADA (Jurnal Sist. Inf. dan Manaj. Basis Data), vol. 1, no. 1, pp. 21-30, 2018.

[27] A. S. Putra, H. Sukri, and K. Zuhri, "Sistem Monitoring Realtime Jaringan Irigasi Desa (JIDES) Dengan Konsep Jaringan Sensor Nirkabel," IJEIS (Indonesian J. Electron. Instrum. Syst., vol. 8, no. 2, pp. 221-232.

[28] D. P. Sari, O. M. Febriani, and A. S. Putra, "Perancangan Sistem Informasi SDM Berprestasi pada SD Global Surya," in Prosiding Seminar Nasional Darmajaya, 2018, vol. 1, no. 1, pp. 289-294. 